\title{
A CONSTRUÇÃO METODOLÓGICA DO PROJETO EMPREENDEDORISMO NA ESCOLA
}

\section{THE METHODOLOGICAL DEVELOPMENT OF THE OUTREACH PROJECT ENTREPRENEURSHIP AT SCHOOL}

\author{
Monique Scalco Soares Siqueira* \\ ORCID: https://orcid.org/0000-0001-8957-9933 \\ Daniela Meirelles Andrade** \\ ORCID: https://orcid.org/0000-0001-7893-4629 \\ Gabrielly Fernandes Ribeiro*** \\ ORCID: https://orcid.org/0000-0002-9232-3012 \\ Ana Luisa Fonseca Valério**** \\ ORCID: https://orcid.org/0000-0001-8007-8286 \\ Priscilla Oliveira Nascimento***** \\ ORCID: https://orcid.org/0000-0003-3355-0685
}

\section{Resumo}

O objetivo deste artigo é apresentar a metodologia utilizada na fase piloto do projeto de extensão Empreendedorismo na Escola. O projeto consiste na realização de curso específico para alunos do $9^{\circ}$ ano, que estão em processo de escolha dos rumos de suas vidas, com foco em possível empregabilidade. $\mathrm{O}$ curso foi aplicado em uma escola municipal de uma cidade do sul de Minas Gerais, durante o segundo semestre de 2018. Para a execução do projeto, a equipe elaborou distintos materiais, como apostila para os alunos e para os professores que ministraram as aulas, cartilha, slides, além de diferentes atividades e dinâmicas. Os envolvidos no projeto também trabalharam na realização da I Feira de Empreendedores Mirins, considerada a culminância do Projeto. O Projeto demonstrou aos estudantes que empreender desde jovem é possível, revelando as habilidades e competências de cada um deles, além de apresentar novas perspectivas sobre a empregabilidade e a vivência no meio social.

Palavras-chave: Empreendedorismo. Projeto de Extensão. Inovação. Metodologia de Execução. Ensino Fundamental.

\begin{abstract}
The purpose of this article is to describe the methodology used in the pilot phase of the outreach project Entrepreneurship at School. The project conducted a specific course for 9th grade students who are in the process of choosing their own path in life, with a the focus on possible employability. The course was carried out in a municipal school in a city in the south of Minas Gerais, during the second semester of 2018. For the project development, the team prepared different materials, such as booklet for the students and teachers who taught the classes, handouts, slides in addition to different activities and dynamics. Those involved in the project also organized the $1^{\text {st }}$ Fair of Young Entrepreneurs which was the culmination of the project. It demonstrated to the students that it is possible to undertake at young age, revealing their skills and competences as well as presenting new perspectives on employability and living in the social environment.
\end{abstract}

Keywords: Entrepreneurship; Outreach project; Innovation; Development methodology; Elementary school.

Data recebimento: 09/03/2021

Data de aceite: 06/08/2021
* Aluna de Doutorado da Universidade Federal de Lavras (UFLA), Lavras - MG, Brasil. E-mail: moniquescalco@gmail.com ** Professora da Universidade Federal de Lavras (UFLA), Lavras - MG, Brasil. E-mail: daniela.andrade@dae.ufla.br

*** Aluna de Graduação da Universidade Federal de Lavras (UFLA), Lavras - MG, Brasil. E-mail: gabrielly.ribeiro@estudante.ufla.br **** Aluna de Graduação da Universidade Federal de Lavras (UFLA), Lavras - MG, Brasil. E-mail: ana.valerio@estudante.ufla.br ***** Aluna de Doutorado da Universidade Federal de Lavras (UFLA), Lavras - MG, Brasil. E-mail: priscilla.juridico.vga@hotmail.com 


\section{Introdução}

A Universidade tem três funções basilares, quais sejam: ensino, pesquisa e extensão. A Constituição Federal (BRASIL, 1988) estabelece que esse tripé é regido pelo princípio da indissociabilidade, devendo isso ser tratado de modo igualitário pela Universidade. Neste artigo, discutese a relevância da extensão, trazendo como fenômeno de análise o projeto Empreendedorismo na Escola, realizado pela Universidade Federal de Lavras (UFLA), em parceria com o Departamento de Administração e Economia (DAE) e o Núcleo de Inovação, Empreendedorismo e Setor Público (NIESP), o qual tangibiliza o caráter complementar ao ensino e à pesquisa.

A extensão universitária exerce um papel fundamental na vida dos acadêmicos, os quais têm a oportunidade de praticar os conhecimentos adquiridos na universidade. Também tem importante impacto sobre a vida da comunidade, a qual usufrui deste aprendizado. Essa interação entre universidade e sociedade possibilita o fortalecimento da relação entre as partes e promove a efetivação do compromisso social da universidade (RODRIGUES et al., 2013). De Paula (2013) observa que a extensão convoca a universidade para o aperfeiçoamento de sua função enquanto instituição envolvida com a transformação social.

O projeto Empreendedorismo na Escola começou em 2015, por iniciativa e coordenação da professora Daniela Meirelles Andrade, o qual é composto por alunos da graduação e pós-graduação do curso de Administração Pública. Tem-se como público-alvo estudantes do $9^{\circ}$ ano do ensino fundamental. Busca-se trabalhar a temática do empreendedorismo, muitas vezes desconhecida pelos alunos, de forma interativa e dinâmica, e despertar nos estudantes o interesse pelas práticas empreendedoras, de modo a torná-los aptos a identificar uma oportunidade e propor um novo pensar em relação aos problemas que os cercam. Assim, os alunos são incitados a transformar a realidade onde estão inseridos, através de uma ideia inovadora, maior engajamento na participação social ou mesmo pela mudança de pensamento.

Após a análise dos resultados gerais do projeto, o grupo concluiu ser o momento de desenvolver uma atuação mais aprofundada e longitudinal da temática do empreendedorismo. Para atender a esse propósito, o projeto foi reestruturado e as atividades passaram a ser concentradas em apenas uma escola, a fim de perceber se as intervenções ocorridas gerariam transformações no agir dos envolvidos, por meio de ações empreendedoras ou do comportamento empreendedor entre os alunos beneficiados. O objetivo central da segunda etapa do projeto foi o desenvolvimento de um curso específico para atender alunos em processo de decisão e escolha dos rumos de suas vidas, com foco em uma possível empregabilidade.

Diante disso, selecionou-se uma escola municipal de uma cidade do sul de Minas Gerais para a realização do projeto piloto, ao longo do segundo semestre de 2018 , nas turmas do $9^{\circ}$ ano. Ante o exposto, este artigo tem como objetivo apresentar o processo metodológico utilizado para o desenvolvimento do projeto. Este aspecto é fundamental para inspirar outras iniciativas em diferentes contextos brasileiros, o que, ao mesmo tempo, torna-se o elemento que justifica a relevância e a contribuição do projeto, tanto do ponto de vista social, na medida em que 
transforma atores que fazem parte da sociedade, bem como metodológico, por apresentar o caminho percorrido pelo projeto, podendo ser inspiração para outros pesquisadores.

Assim, são primeiramente apresentados alguns aspectos do empreendedorismo social e da importância da incorporação da postura empreendedora durante o período escolar. $\mathrm{Na}$ sequência, apresenta-se a metodologia utilizada pelo projeto, compreendendo as etapas realizadas para reformulação e sua implementação. Logo após, são discutidos os resultados dessa ação extensionista e, finalmente, as considerações finais são apresentadas.

\section{Empreendedorismo Social como instrumento de transformação social}

Na década de 1990, surgiu nos Estados Unidos o conceito de empreendedorismo social, o qual tem despertado crescente interesse da comunidade acadêmica, além de ser considerado um elemento fundamental da agenda de desenvolvimento do século XXI (ABDO; PARIS, 2017). Diferente do empreendedorismo tradicional, que visa principalmente o lucro, o empreendedorismo social busca resoluções para problemas que afligem a sociedade (MURAD; CAPPELLE; ANDRADE, 2020).

Mair e Martí (2006) explicam que o termo se refere a um processo que estimula a umdança social e responde às carências relevantes da sociedade, não sendo tomada por incentivos financeiros diretos para os empreendedores. Assim, os autores afirmam que o empreendedorismo social é entendido de forma distinta de outros modos de empreendedorismo, tendo em vista a predileção conferida à promoção do valor social.

Peredo e McLean (2006) apontam que o empreendedorismo social é realizado onde uma pessoa ou um grupo de pessoas buscam unicamente, ou de forma prioritária, a criação de valor social de algum tipo, seguindo esse propósito através de alguma combinação, identificando e investigando oportunidades para criar valor, aplicar inovação, suportar riscos e declinar-se a consentir limitações nos recursos disponíveis.

Consoante Oliveira (2004), o empreendedorismo social é uma ação inovadora direcionada para o âmbito social, em que o processo começa a partir da percepção do problema local e a busca em se propor uma forma de resolução. Assim sendo, o autor explica que o conceito envolve alguns atributos basilares, quais sejam: " $1 .^{\circ}$ ) ser inovadora; $2 .^{\circ}$ ) ser realizável; $3^{\circ}$ ) ser autossustentável; $4^{\circ}$ ) envolver várias pessoas e segmentos da sociedade, principalmente a população atendida; $5^{\circ}$ ) provocar impacto social e permitir que seus resultados possam ser avaliados" (OLIVEIRA, 2004, p. 15).

É nesse contexto que foi proposto o projeto Empreendedorismo na Escola. Observase que a escola é um ambiente ideal para inserir conceitos do empreendedorismo e incentivar as crianças e jovens a promoverem mudanças nos diferentes ambientes que os cercam. Parte- 
se da premissa de que o empreendedorismo pode ser ensinado e assimilado pelo indivíduo, instruindo as pessoas a sair da zona de conforto e buscar transformar e melhorar a realidade onde estão inseridos, através da proposição de ideias inovadoras, por meio de maior engajamento na participação social e/ou pela mudança de pensamento.

Souza (2012) observa que a necessidade de se lecionar sobre o empreendedorismo nas instituições de ensino básico tem sido cada vez mais discutida na literatura. A autora defende a incorporação da disciplina no currículo escolar, tendo em vista que a inserção do tema empreendedorismo proporciona uma nova maneira de enxergar, detectar e encarar as oportunidades e as necessidades que aparecem ao longo da vida. Por meio da educação empreendedora, é possível implementar uma cultura empreendedora, a qual enseja a melhoria do desenvolvimento socioeconômico.

Para Dolabela e Filion (2013), a introdução da educação empreendedora nas escolas muda a forma de ser, fazer, lidar e resolver as diversas situações. Por ser um tema transversal, ensinar o caminho para os alunos se tornarem empreendedores promove o desenvolvimento social, econômico e individual. Desse modo, a educação empreendedora promove a mudança na forma como as pessoas pensam e agem, gerando impactos sociais e econômicos.

Nesse sentido, o projeto propõe um novo olhar aos alunos, revelando as habilidades e competências de cada um deles, além de apresentar novas perspectivas sobre a empregabilidade. Busca-se apresentar uma visão ampliada sobre os caminhos que podem ser percorridos ao longo da vida dos diferentes estudantes. Incentivar o empreendedorismo no ambiente escolar é promover valores de trabalho em equipe, o crescimento pessoal e a valorização da educação.

\section{Metodologia}

O projeto piloto foi aplicado ao longo do segundo semestre de 2018, sendo que toda a construção foi pensada a partir de alunos da rede pública que estivessem finalizando o ensino fundamental 2. É comum os jovens terem, nessa fase, uma série de inquietações, como: o que vou fazer da vida após encerrar o ensino médio? Irei tentar a Universidade? Isso é possível para mim? Faz parte da minha realidade? É possível trabalhar com minha mãe ou meu pai? O que posso fazer para agregar ao que eles fazem? Como criar o meu emprego? Assim, o projeto foi idealizado com o propósito de contribuir com os alunos em suas escolhas de vida, buscando auxiliá-los na resposta a esses questionamentos.

A construção do projeto aconteceu de forma coletiva, por meio da interação entre os membros e a professora coordenadora do projeto, sempre priorizando a criação de materiais antes da aplicação prática na sociedade a ser beneficiada. Esse processo envolveu amadurecimento e dedicação da equipe. Assim, a preparação do projeto piloto durou alguns meses 
antes de sua execução, uma vez que o processo envolveu leitura, discussão, produção, avaliação e aperfeiçoamento de todo material do curso, além do preparo e treinamento da equipe executora.

Nesta seção, são abordadas todas as etapas realizadas para reformulação e implementação do projeto piloto Empreendedorismo na Escola, quais sejam: definição da nova estrutura; definição de responsabilidades temáticas; capacitação; construção das aulas; apresentação e reorganização das aulas; feedbacks da postura a ser utilizada nas aulas; execução do projeto; reuniões para avaliação das aulas dadas e apresentação das aulas vindouras; organização da I Feira de Empreendedores Mirins; avaliação projeto. Essas etapas são detalhadas na seção seguinte.

\section{Etapas para a realização do Projeto Piloto}

A realização do projeto piloto contou com diversas etapas, as quais são discutidas a seguir. O primeiro passo foi a realização de avaliação e fechamento da primeira parte do projeto, referente ao período entre 2015 e 2017, tendo como objetivo a discussão dos resultados obtidos até o momento. Nesse período, as visitas às escolas eram sempre acompanhadas da aplicação de questionários, visando compreender o grau de satisfação dos estudantes em relação ao projeto. Foi a partir dessa avaliação que o grupo percebeu a necessidade de atuação mais aprofundada e longitudinal da temática do empreendedorismo no contexto escolar.

Em seguida, tendo em vista a percepção do grupo em relação à necessidade de aprofundar mais o assunto, foi definida uma nova estrutura para o projeto. Assim, as atividades deixaram de ser aplicadas de forma sucinta em diversas escolas para se concentrar em apenas uma escola. Nessa etapa, foram definidos os materiais necessários para a realização dessa nova versão, quais sejam: apostilas para alunos e professores, cartilha, slides referentes a cada capítulo, além da elaboração de diferentes atividades e dinâmicas.

Em conjunto com a definição da nova estrutura do projeto, foram delegadas as responsabilidades temáticas de cada membro. Assim, definiram-se os temas que deveriam ser tratados e cada membro ficou responsável pela elaboração de duas a três aulas. Os temas são: história do empreendedorismo; características do empreendedor; oportunidade x necessidade; participação social; empreendedorismo social; empreendedorismo público e intraempreendedorismo; inovação e mudança; modelo de negócio e, por fim, plano de negócio. Nesse momento, foi definido também que alguns temas seriam ministrados em apenas uma aula e outros seriam divididos em mais aulas, tendo em vista ser um conteúdo mais extenso.

Para que todos os membros estivessem habilitados para atuar em sala de aula, com autoconfiança, didática e conhecimento, foi realizado um extenso processo de capacitação. Primeiramente, os membros foram direcionados à leitura de diversos artigos e livros que abordavam a temática do empreendedorismo, a fim de se familiarizarem com o tema. Na sequência, houve a realização de workshop, que consistiu em treinamento e discussão sobre a temática 
do empreendedorismo, em que vários temas foram colocados em pauta, de modo a inteirar os membros quanto aos objetivos do projeto e as formas para alcançá-lo. As leituras e discussões realizadas durante o workshop foram capazes de embasar a criação dos materiais.

Nos dias 21 e 22 de fevereiro de 2018, ocorreu um evento denominado "Empreendedorismo na escola: construção e reconstrução de práticas de ensino e aprendizagem”, em que os membros discutiram a nova versão do projeto e apresentaram os materiais elaborados até aquele momento. No evento, cada membro apresentou o tema pelo qual ficou responsável, simulando a ministração de uma aula, a fim de ser orientado quanto à postura em sala de aula, aperfeiçoando-se, assim, a didática de cada um. Os materiais passaram por intensas modificações, a fim de melhor adequá-los ao perfil do público-alvo. Vale ressaltar que essa foi a primeira etapa de correção das aulas.

Após diversos encontros, muitas leituras e discussões, bem como sucessivas alterações nos materiais elaborados pelos membros do projeto, a equipe se sentiu apta a entrar em campo e partir para a aplicação do curso, o qual foi ministrado nas três turmas do $9^{\circ}$ ano do ensino fundamental, contemplando 75 alunos. Assim, a execução do projeto teve início em agosto de 2018, com encontros semanais, nos últimos horários, em dias intercalados da semana, a fim de não comprometer a grade curricular dos alunos. Em cada encontro, eram realizadas atividades distintas, como aulas expositivas, dinâmicas fora da sala de aula, exposição de vídeos e filmes, e outras atividades visando a interação dos alunos e a maior fixação do tópico abordado. Vale ressaltar que a equipe também realizou encontros semanais, com o objetivo de discutir o andamento do projeto e apresentar as aulas vindouras.

Os estudantes também foram incentivados a elaborar seu próprio projeto empreendedor, o qual seria apresentado ao final do curso, durante a I Feira de Empreendedores Mirins. Assim, eles foram orientados de que poderiam propor uma ação de empreendedorismo privado, público ou social. As aulas eram sempre direcionadas a essa atividade, incentivandoos a serem empreendedores, exercendo a criatividade e o trabalho em equipe. Os alunos também trabalharam na elaboração de seu próprio plano de negócio e no modelo de negócio.

Por fim, a culminância do projeto consistiu na realização da I Feira de Empreendedores Mirins, a qual foi dividida em duas etapas, quais sejam: apresentação na própria escola e, na semana seguinte, os alunos apresentaram na UFLA. Findo o Projeto, foram distribuídos questionários aos alunos, professores e aos próprios membros, com o objetivo de obter um feedback em relação a ele. Em seguida, os dados foram tabulados e realizada análise descritiva.

Todas as informações relacionadas ao projeto foram registradas em relatório. Foi realizada reunião de fechamento em dezembro, em que todos os membros relataram sua percepção sobre o projeto e fizeram propostas de melhorias. O Quadro 1 apresenta as etapas do projeto, assim como uma breve descrição de cada uma. 
Quadro 1 - Etapas do Projeto piloto.

\begin{tabular}{|c|c|c|}
\hline O quê & Como & Quando \\
\hline $\begin{array}{l}\text { Avaliação e } \\
\text { fechamento da } \\
\text { primeira etapa }\end{array}$ & $\begin{array}{l}\text { Avaliação dos resultados obtidos entre } 2015 \text { e } 2017 \text {, referente à } \\
\text { primeira versão do projeto e fechamento dessa etapa. }\end{array}$ & Final de 2017. \\
\hline $\begin{array}{l}\text { Definição da nova } \\
\text { estrutura }\end{array}$ & $\begin{array}{l}\text { Atividades deixaram de ser aplicadas de forma sucinta em diversas } \\
\text { escolas para se concentrar em apenas uma escola. Definição da } \\
\text { nova estrutura do projeto e os materiais necessários para a sua } \\
\text { realização. }\end{array}$ & $\begin{array}{l}\text { Novembro de } \\
2017 .\end{array}$ \\
\hline $\begin{array}{l}\text { Definição de } \\
\text { responsabilidades } \\
\text { temáticas }\end{array}$ & $\begin{array}{l}\text { Determinação dos temas que seriam ministrados, bem como os } \\
\text { membros responsáveis pela elaboração dos materiais relacionados } \\
\text { a cada tema. }\end{array}$ & $\begin{array}{l}\text { Novembro de } \\
2017 .\end{array}$ \\
\hline Capacitação & $\begin{array}{l}\text { Leitura de diversos artigos e livros que abordavam a temática do } \\
\text { empreendedorismo, a fim de familiarizar com o tema; realização de } \\
\text { Workshop, com treinamento e discussão sobre empreendedorismo. }\end{array}$ & Contínuo. \\
\hline Construção das aulas & $\begin{array}{l}\text { Elaboração de apostilas para os alunos e para os professores, } \\
\text { cartilha, slides referentes a cada capítulo, diferentes atividades e } \\
\text { dinâmicas; preparação para a Feira de Empreendedores Mirins. }\end{array}$ & $\begin{array}{l}\text { Primeiro } \\
\text { semestre de } \\
2018 .\end{array}$ \\
\hline $\begin{array}{l}\text { Apresentação e } \\
\text { reorganização das } \\
\text { aulas }\end{array}$ & $\begin{array}{l}\text { Realização de reuniões semanais entre os membros do grupo, a fim } \\
\text { de apresentar cada aula. Avaliação do conteúdo, a forma de } \\
\text { apresentação, os slides, bem como as atividades propostas; } \\
\text { correção do material, de forma a melhor atender os estudantes. }\end{array}$ & Semanal. \\
\hline $\begin{array}{l}\text { Feedbacks da postura } \\
\text { a ser utilizada nas } \\
\text { aulas }\end{array}$ & $\begin{array}{l}\text { Simulação da ministração das aulas para os próprios membros do } \\
\text { Projeto; identificação de elementos que dificultavam a ministração } \\
\text { da aula. }\end{array}$ & Semanal. \\
\hline Execução do Projeto & $\begin{array}{l}\text { Início em agosto de 2018; encontros semanais nos últimos } \\
\text { horários, sendo em dias intercalados da semana, a fim de não } \\
\text { comprometer a grade curricular dos alunos; em cada encontro, } \\
\text { eram realizadas atividades distintas, como aulas expositivas, } \\
\text { dinâmicas fora de sala de aula, exposição de vídeos e filmes, e } \\
\text { outras atividades, visando a interação dos alunos e maior fixação } \\
\text { do tema proposto. }\end{array}$ & $\begin{array}{l}\text { Agosto a } \\
\text { novembro de } \\
2018 .\end{array}$ \\
\hline $\begin{array}{l}\text { Avaliação das aulas } \\
\text { dadas e apresentação } \\
\text { das vindouras. }\end{array}$ & $\begin{array}{l}\text { Reuniões semanais para avaliar as aulas dadas, apresentar as aulas } \\
\text { vindouras e discutir sobre o andamento do projeto. }\end{array}$ & Semanal. \\
\hline $\begin{array}{l}\text { Organização e } \\
\text { execução da I Feira de } \\
\text { Empreendedores } \\
\text { Mirins }\end{array}$ & $\begin{array}{l}\text { Reuniões tratando especificamente sobre a organização deste } \\
\text { evento; realização da I Feira de Empreendedores Mirins, a qual foi } \\
\text { dividida em duas etapas, quais sejam: apresentação na própria } \\
\text { escola e na semana seguinte, os alunos apresentaram na UFLA; }\end{array}$ & $\begin{array}{l}\text { Outubro e } \\
\text { novembro. }\end{array}$ \\
\hline $\begin{array}{l}\text { Avaliação da segunda } \\
\text { etapa do projeto }\end{array}$ & $\begin{array}{l}\text { Avaliação do Projeto conforme a percepção dos membros, dos } \\
\text { profissionais da escola e dos alunos. }\end{array}$ & $\begin{array}{l}\text { Dezembro de } \\
2018 .\end{array}$ \\
\hline
\end{tabular}

Fonte: Elaboração dos autores (2019). 


\section{Resultados}

Nesta seção, são apresentados os resultados do processo de construção e execução do projeto Empreendedorismo na Escola, quais sejam: manual do aluno e manual do professor, cartilha, slides e a realização da I Feira de Empreendedores Mirins. Ao longo da descrição dos resultados, são apresentadas algumas fotografias, sendo que a imagem do rosto dos alunos foi suprimida, de modo a garantir o anonimato deles.

\section{1 - Manual do aluno e do professor}

No manual do professor, cada capítulo dispõe de conteúdo teórico, um guia para a ministração da aula com um passo-a-passo para a explicação dos slides e uma explanação sobre a atividade a ser aplicada ao final.

Já o manual do aluno dispõe de figuras, informações resumidas sobre o tema e a atividade de fixação. Todos os capítulos começam com alguma pergunta em relação ao assunto da aula, instigando os alunos a refletirem sobre o conteúdo. Também contém informações curiosas sobre o tema, denominado "Saiba mais", com link de sítios e vídeos, nome de livros, filmes e outras informações complementares.

Os manuais contêm 9 capítulos, cada qual com um tema diferente, os quais são tratados a seguir.

\section{1 - História do empreendedorismo}

Esse capítulo teve como objetivo apresentar aos alunos a parte historiográfica do empreendedorismo e explicar o que é empreender e o que o empreendedor faz. Assim, explica-se que, no decorrer do tempo, ocorreram diversas tentativas de definição do que seria empreendedorismo e quais as especificidades do empreendedor, no entanto, até hoje não há consenso na literatura quanto à definição do termo (COSTA; BARROS; MARTINS, 2008).

Consoante Borges, Lima e Brito (2017), o fenômeno do empreendedorismo tem despertado grande interesse de diferentes atores, cuja definição envolve a relação entre os conceitos empreendedorismo e empreendedor. Assim, tem-se, de um lado, as inferências sociais e econômicas, especialmente relacionadas à descoberta ou criação de oportunidades, assim como o processo empreendedor, e, por outro, o indivíduo empreendedor.

Baggio e Baggio (2014, p. 27) afirmam que, a partir dos conceitos apresentados por renomados autores, são elementos em comum que caracterizam o empreendedor: "iniciativa para criar um novo negócio e paixão pelo que faz; utiliza os recursos disponíveis de forma criativa transformando o ambiente social e econômico onde vive; aceita assumir os riscos e a possibilidade de fracassar". 
Essa aula foi muito importante para apresentar o tema do curso aos alunos e despertarlhes o interesse em saber mais sobre o assunto, além de destacar a importância do empreendedor ao longo da história, trazendo exemplos de empreendedores desde o Barão de Mauá, do século XIX, até Steve Jobs, criador da Apple, os quais chamaram a atenção dos estudantes. Ao final do capítulo, propôs-se o preenchimento de uma cruzadinha para fixar o conteúdo.

\section{2 - Características do empreendedor}

O segundo tópico trata das características necessárias para que alguém seja um empreendedor. O capítulo inicia instigando os alunos a imaginarem o que é preciso para que alguém se identifique como empreendedor. O capítulo aborda os estudos de Schmidt e Bohnenberger (2009), os quais analisaram algumas características que um empreendedor precisa ter, como, por exemplo, saber detectar as oportunidades, planejar e monitorar as coisas de forma sistêmica, saber calcular os riscos, ser sociável, saber ser um bom líder, como também ser alguém persistente e autoeficaz.

Esse capítulo teve como objetivo mostrar aos alunos as características necessárias para que alguém possa ser um bom empreendedor, revelando cada ponto essencial para a construção desse potencial. Para tanto, propôs-se como atividade a realização de um teste para verificar se os alunos possuíam um perfil empreendedor e, a partir dos resultados, analisar os elementos que poderiam ser melhorados para se tornarem empreendedores. Ao final, os alunos foram convidados a explanar sobre os resultados para serem discutidos com os colegas e professores.

\section{3 - Oportunidade $x$ necessidade}

O capítulo 3 traz aos alunos os conceitos de empreendedorismo por oportunidade versus necessidade. Embora Vale, Corrêa e Reis (2014, p. 314) reconheçam que os motivos que levam um indivíduo a empreender sejam múltiplos, indo além dessa dualidade entre oportunidade e necessidade, incluindo "oportunidade, atributos pessoais, mercado de trabalho, insatisfação com emprego, família e influência externa", optou-se, nesse capítulo, em abordar apenas dois motivos, por ser mais didático, e por não haver tempo para aprofundar nessa discussão. A Fotografia 1 retrata a ministração dessa aula. 
Fotografia 1 - Ministração da aula.

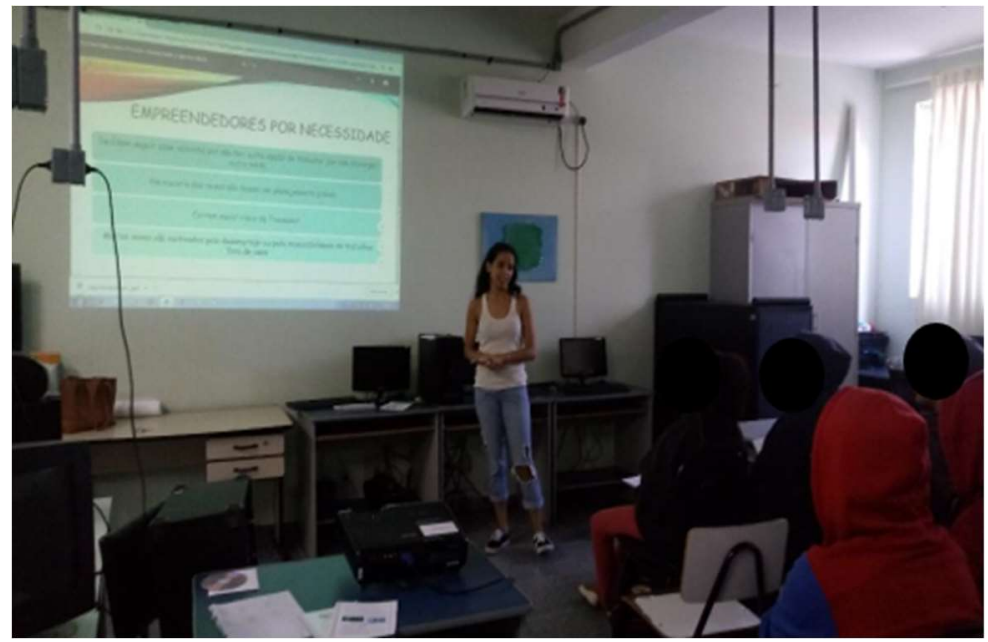

Fonte: Arquivos da pesquisa (2019), dados do projeto.

Buscou-se demonstrar aos alunos que, independentemente da situação, o empreendedor deve saber utilizar as situações ao seu redor a seu favor. Para tanto, foram mencionados os exemplos do criador e idealizador do Facebook e do criador da Cacau Show, mostrando-se contextos totalmente distintos, mas que obtiveram êxito. Para finalizar a aula, os alunos realizaram atividade que consistiu em perguntas sobre o tema apresentado.

\section{4 - Participação social}

O quarto capítulo tem como tema a participação social, e traz a discussão sobre a sua importância e quais os instrumentos existentes para que as pessoas possam participar de questões sociais. Assim, a primeira pergunta realizada aos alunos é: qual a relação da participação social com o empreendedorismo? A participação social implica sair da zona de conforto, ou seja, buscam-se mudanças e melhorias na sociedade. No empreendedorismo, a ideia é semelhante, pois o empreendedor está sempre em busca de oportunidades e de propor ideias e ações inovadoras, e isso é conquistado pela busca contínua de sair do comodismo e adquirir e absorver novas informações, para serem usadas em seu empreendimento.

A participação social se refere às iniciativas de inserção da sociedade na gestão de políticas públicas, com o intuito de "atender um anseio da própria população por integrar processos de tomadas de decisão levando diretamente ao governo suas demandas" (SIMÕES; SIMÕES, 2015, p. 2). A partir disso, a sociedade pode levar diretamente ao Estado suas demandas, sendo as políticas públicas delineadas de modo a melhor atender aos interesses da coletividade. Busca-se, por meio da participação direta, dar "voz" à sociedade para realizar propostas, questionamentos e levar ao Estado suas reais necessidades. 
A dinâmica proposta foi a apresentação de problemas aos alunos, e estes deveriam propor formas para solucioná-los, através de um plano de ação. Assim, a perspectiva da necessidade da participação social se estabeleceu por completo, tanto na prática como nos resultados.

\section{5 - Empreendedorismo social}

O capítulo 5 apresenta a discussão sobre empreendedorismo social, explicando aos alunos que, diferentemente do empreendedorismo tradicional, motivado por questões econômicas, o empreendedorismo social busca atender às necessidades sociais e criação de valor social (MURAD; CAPPELLE; ANDRADE, 2020; MAIR; MARTI, 2006; PEREDO; MCLEAN, 2006).

Essa aula contou com a apresentação de vídeo, gravado no programa Altas Horas, referente a um estudante de Engenharia Civil que propôs a ação Moradigna, a qual visa solucionar os problemas estruturais das casas dos moradores que residem na comunidade Jardim Pantanal, localizada em São Paulo. A Fotografia 2 retrata a ministração da aula.

Fotografia 2 - Ministração da aula.

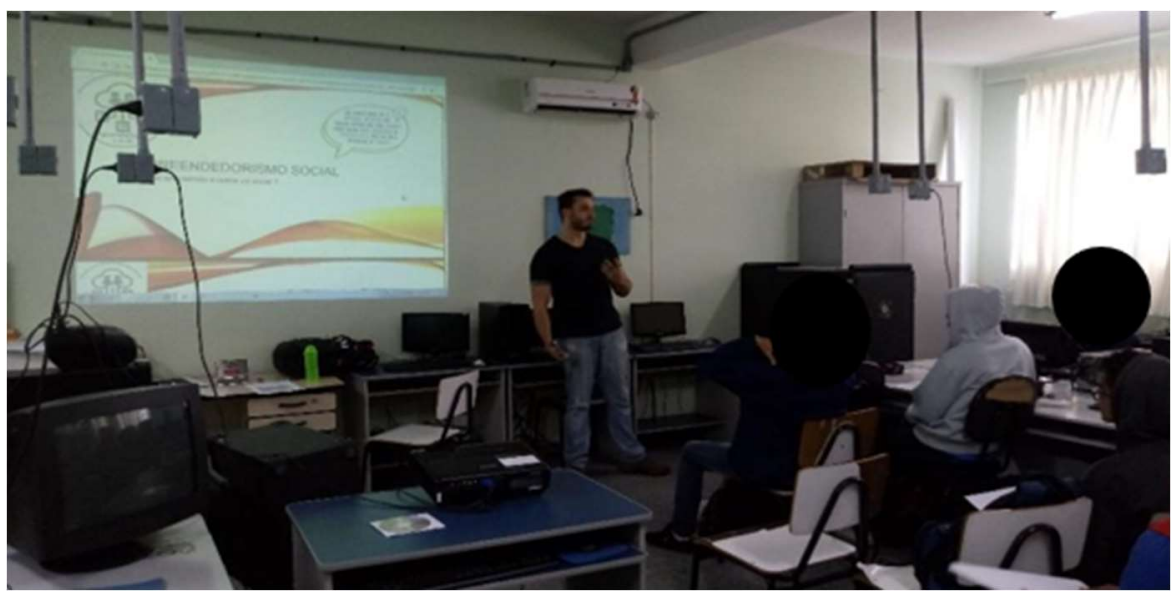

Fonte: Arquivos da pesquisa (2019), dados do projeto.

Após assistirem ao vídeo, os alunos foram convidados a responder perguntas relacionadas ao programa Moradigna e ao próprio bairro também, quais sejam: qual era o problema encarado pelos moradores da comunidade Jardim Pantanal? Qual foi a solução encontrada para solucionar o problema apresentado? Em seu bairro, possui algum problema parecido? O que você faria para solucionar este problema diagnosticado por você? A partir disso, os alunos foram instigados a pensar nos problemas encontrados no seu contexto e propor soluções. 


\section{6 - Empreendedorismo público e intraempreendedorismo}

Esse capítulo foi construído para incentivar os alunos a pensarem sobre os problemas decorrentes do seu cotidiano, bem como de todo âmbito público, e serem agentes de mudança. Elaborou-se, inicialmente, uma discussão sobre a burocracia e, na sequência, tratou-se sobre o intraempreendedorismo.

Assim, explicou-se aos alunos que Weber é considerado o precursor do modelo burocrático por ter analisado e sintetizado suas principais características (SECCHI, 2009). Secchi (2009) afirma que as características da administração burocrática podem ser resumidas em três: formalidade, impessoalidade e profissionalismo. No entanto, o autor observa que surgiram diversas críticas em relação ao modelo burocrático, em virtude das disfunções burocráticas e seus impactos negativos às organizações.

Nesse sentido, buscou-se demonstrar aos alunos que as organizações podem funcionar em aparatos burocráticos e, ainda sim, serem inovadoras. É nesse momento que entra a importância do comportamento intraempreendedor, que consiste na busca por novas perspectivas no meio em que está inserido, mesmo dentro de uma organização com limites já estabelecidos.

A dinâmica foi fundamental para uma melhor compreensão do tema, em que os alunos se dividiram em grupos e simularam o papel de um gestor público. O professor ofereceu alguns exemplos de órgãos públicos e os estimulou a trabalharem em um problema dessa organização, sob a luz do intraempreendedorismo. Os alunos foram orientados quanto aos procedimentos formais a serem enfrentados. Os resultados obtidos para a resolução dos diferentes problemas foram discutidos com a turma. Buscou-se clarificar que, mesmo em organizações públicas comumente marcadas pelo excesso de formalismo, é possível a transformação empreendedora.

\section{7 - Inovação, mudança e aprendizagem}

Nesse capítulo, apresentou-se aos alunos a importância da inovação, mudança e aprendizagem. Primeiramente, explicou-se que a inovação é impulsionada pelo empreendedorismo e consiste no reconhecimento de oportunidades para realizar algo novo e praticar essas percepções, de modo a elaborar algum tipo de valor (BESSANT; TIDD, 2009). Consoante Drucker (1987), a inovação é um elemento fundamental para os gestores, sendo através dela que a mudança é utilizada enquanto oportunidade. $\mathrm{O}$ autor acrescenta que a inovação pode ser ensinada e aprendida, e, principalmente, praticada. 
Para isso, foram utilizados exemplos próximos à realidade dos estudantes, como a criação do Whatsapp. A fim de melhor compreenderem o tema, os alunos foram convidados a assistir ao filme "Os estagiários", o qual ocorreu em horário extracurricular, conforme demonstra a Fotografia 3.

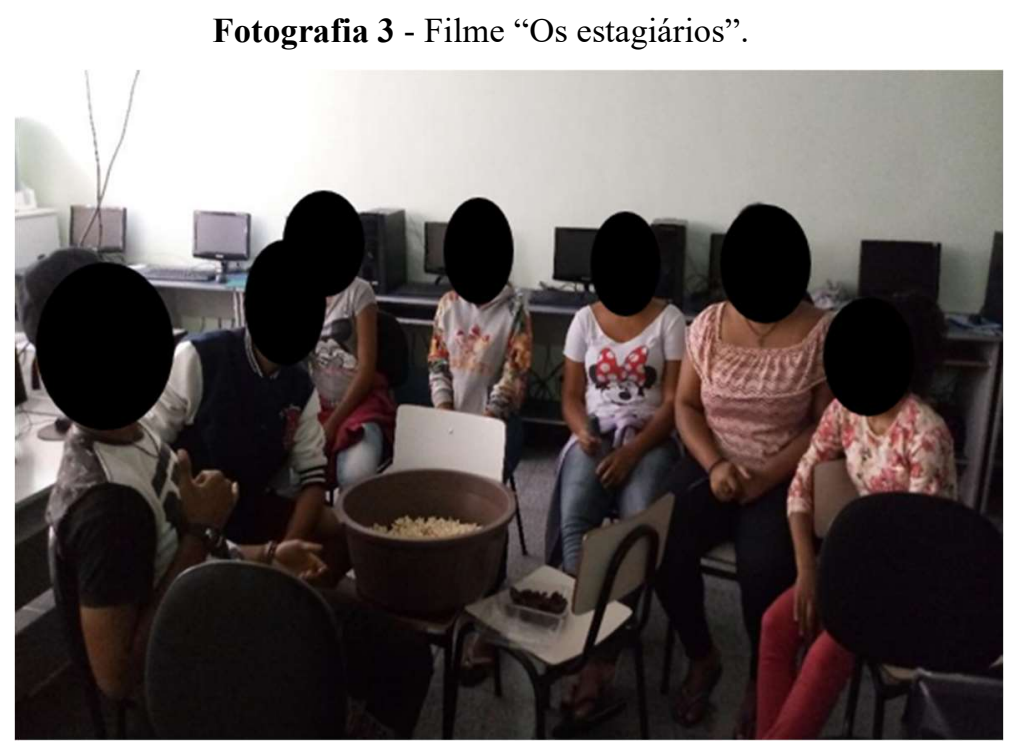

Fonte: Arquivos da pesquisa (2019), dados do projeto.

O filme foi apresentado com o intuito de motivar os alunos a terem atitudes empreendedoras, mesmo diante de situações adversas. Após a exibição do filme, foi possível discutir com eles os conceitos que haviam sido trabalhados em aula, como o trabalho em equipe, a aprendizagem a partir das vivências e da importância de se enfrentarem desafios através de atitudes inovadoras.

\section{8 - Modelo de negócio}

Para auxiliar os alunos a realizarem o projeto final para a feira do empreendedorismo, o objetivo da aula foi apresentar aos estudantes como elaborar um modelo de negócio. Para tanto, os alunos foram ensinados a preencher o Modelo de Negócios Canvas, proposto pelos autores Osterwalder e Pigneur (2010, p.14), os quais o definem como uma "lógica de como uma organização cria, entrega e captura valor". O modelo contém 9 seguimentos, quais sejam: clientes, proposição de valor, canais, relacionamento com clientes, fontes de receitas, recursoschave, atividades-chave, parcerias-chave e estrutura dos custos. 
No decorrer da aula, apresentou-se um exemplo para os alunos, por meio do qual foi possível observar o passo a passo para o preenchimento do modelo Canvas. A dinâmica foi o momento em que cada grupo pôde elaborar o modelo de seu próprio projeto, solidificando o conhecimento aprendido, conforme demonstra a Fotografia 4.

Fotografia 4 - Elaboração do Canvas.

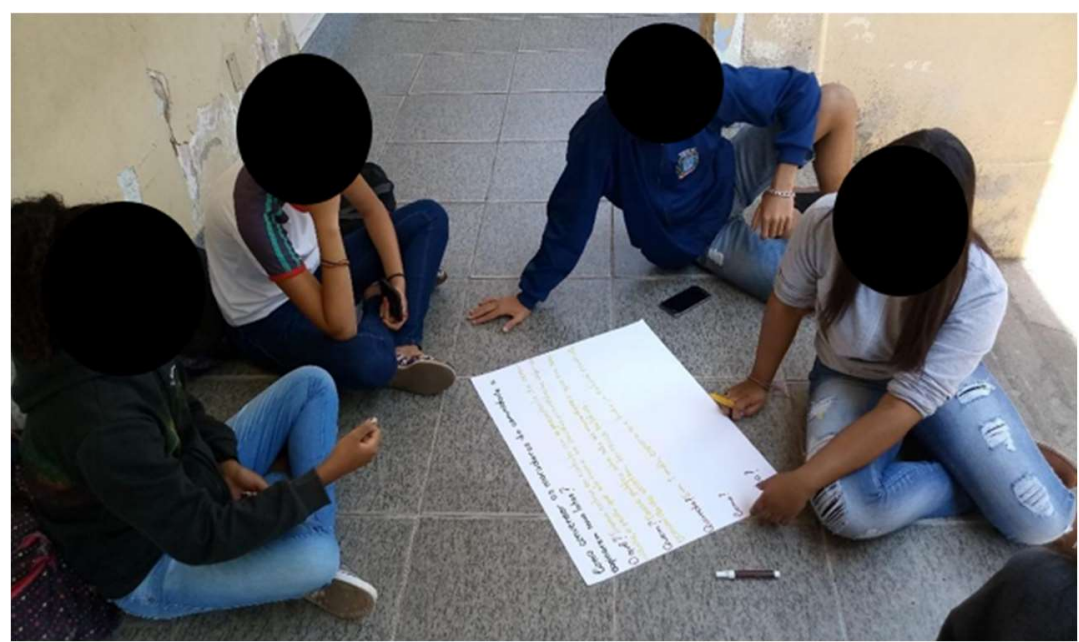

Fonte: Arquivos da pesquisa (2019), dados do projeto.

Para tornar essa atividade mais interativa, utilizaram-se cartolinas e canetas hidrográficas coloridas, enquanto os professores passavam de grupo em grupo, incentivando os alunos a melhorarem suas ideias.

\section{9 - Plano de negócio}

A elaboração de um plano de negócios compreende o estabelecimento dos objetivos do negócio e os passos para alcançá-los, de modo a auxiliar na identificação dos riscos e propor estratégias para minimizá-los e, até mesmo, evitá-los. Para tanto, foram apresentados e discutidos os 4 Ps (produto, preço, praça e promoção) e também a matriz FOFA (forças, oportunidades, fraquezas e ameaças). Assim, a atividade proposta nessa aula foi a identificação dos pontos fortes e fracos dos projetos e a definição de estratégias para melhorar e potencializar os resultados de seus negócios, conforme retrata a Fotografia 5. 
Fotografia 5 - Elaboração do Plano de Negócios.

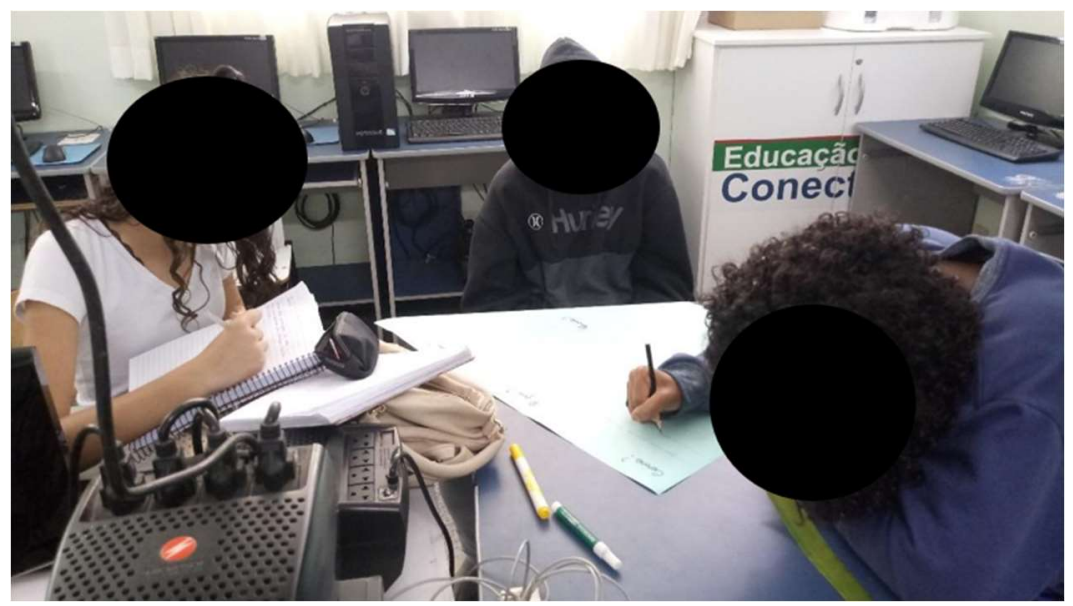

Fonte: Arquivos da pesquisa (2019), dados do projeto.

A realização dessa atividade foi importante, pois possibilitou aos alunos uma análise mais aprofundada dos projetos que seriam apresentados na Feira. Eles também compreenderam a importância de se elaborar um plano de negócio antes de implementar algo novo, de forma a minimizar os seus riscos.

\section{2 - A construção dos slides}

Para tornar o aprendizado dos alunos mais interessante e facilitar o processo de absorção de conteúdo, cada aula contou com uma apresentação em forma de slides contendo exemplos dos conceitos apresentados, imagens ilustrativas e animações.

O primeiro passo foi pensar na padronização estética dos slides. Escolheram-se cores atrativas e vibrantes, que chamam atenção dos espectadores para o conteúdo explorado. $\mathrm{Na}$ sequência, foi definido como padrão em todas as aulas o segundo slide, denominado "Tempestade de Ideias", com a proposta de trazer balões com expressões ou perguntas relacionadas ao tema da aula. A proposta de se fazer uma tempestade de ideias é questionar os alunos sobre aspectos relacionados ao tema da aula, a fim de perceber o nível de conhecimento deles sobre o assunto. 
Dessa forma, a partir do que os alunos respondiam, era possível compreender qual a melhor forma de prosseguir com a aula e quais os melhores exemplos a serem dados, de modo a promover maior compreensão do tema por eles . Por exemplo, se um aluno respondia algo relacionado ao futebol, sendo de conhecimento do professor, ele utilizaria informações relacionadas ao futebol para explicar o tema da aula.

Outrossim, a utilização de exemplos atuais e conexos com a realidade dos alunos foi fundamental para manter a atenção na explicação do professor. $\mathrm{Na}$ aula de intraempreendedorismo, um dos exemplos mencionados aos alunos era referente ao surgimento do Playstation, console muito popular entre os jovens.

Também foram criados slides expostos ao final da aula, chamados "Recapitulando". Trata-se de um conjunto de perguntas aos alunos referente aos tópicos trabalhados na referida aula. Esse slide foi elaborado com o objetivo de estimular os alunos a participarem da aula, bem como contribuir para a fixação do conteúdo, conforme demonstra a Figura 1.

Figura 1 - Slides de fechamento.
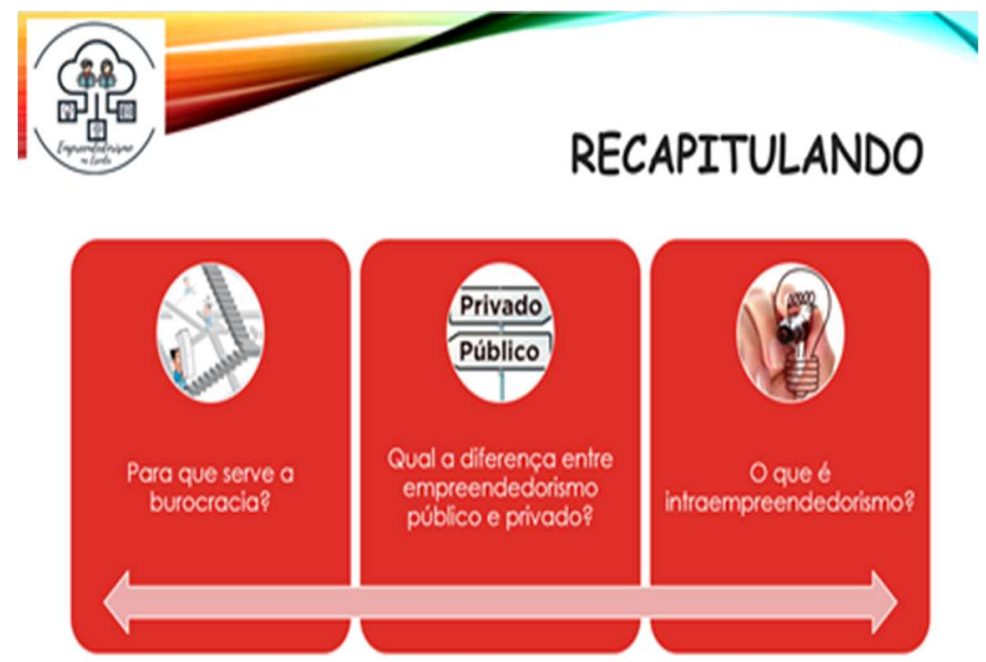

Fonte: Elaboração dos autores (2019), dados do projeto.

\section{3 - Cartilha}

A cartilha está em sua quarta edição e consiste na apresentação de uma história em quadrinhos, em que é apresentado o tema empreendedorismo. As sucessivas versões foram criadas tendo em vista a necessidade de atualizar e trazê-la para uma linguagem mais moderna, 
de modo a atender às demandas dos alunos. Esta foi uma estratégia muito bem aceita pelo público-alvo e atendeu aos resultados esperados.

\section{4 - Feira de Empreendedores Mirins}

A culminância do projeto consistiu na realização da I Feira de Empreendedores Mirins, a qual foi dividida em duas etapas, quais sejam: apresentação na própria escola e na semana seguinte, os alunos apresentaram na UFLA. O objetivo foi incentivar os alunos a exercerem a criatividade, através do desenvolvimento de alguma atividade empreendedora.

A fim de nortear os estudantes para o desenvolvimento dessa atividade, foram trabalhados conceitos relevantes para a estruturação de um negócio, como marketing, estrutura de custos, modelo de negócio, plano de negócio e outros. Assim, no dia 21 de novembro, foi realizada a I Feira de Empreendedores Mirins na escola. Na Fotografia 6, estão presentes os membros do projeto e alunas na pós-graduação da UFLA que foram ao evento para avaliar as atividades apresentadas.

Fotografia 6 - I Feira de Empreendedores Mirins realizado na escola.

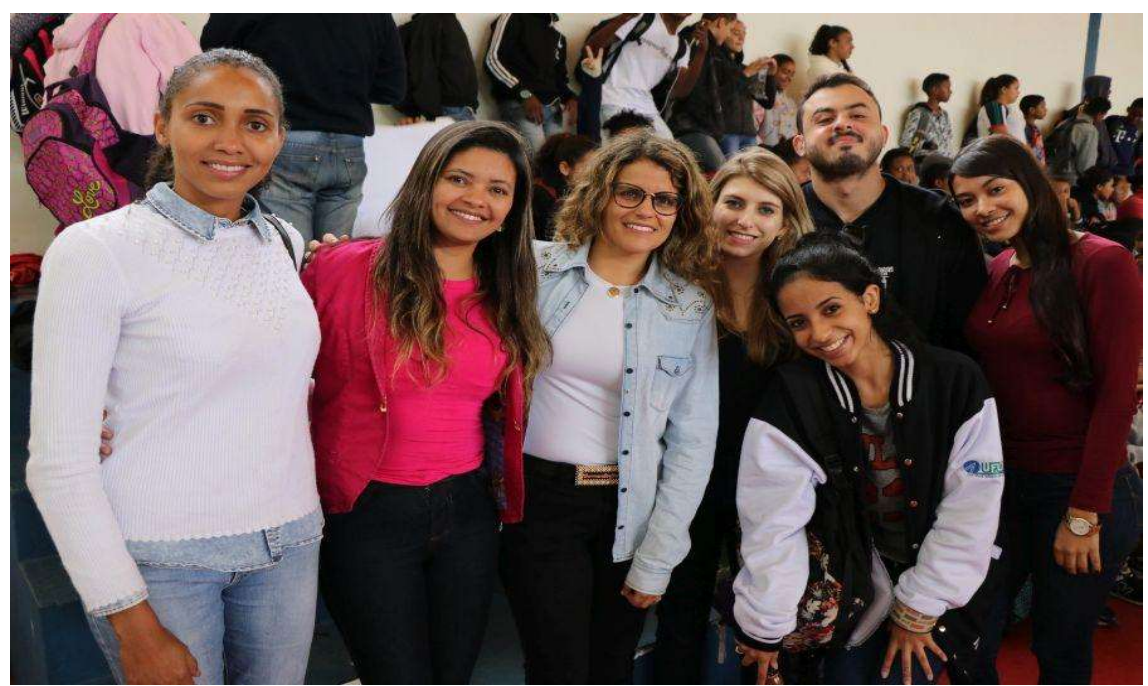

Fonte: Arquivos da pesquisa (2019), dados do projeto.

Já no dia 28 de novembro de 2018, a Feira ocorreu na UFLA, durante o evento "UFLA faz Extensão", o que pode ser visto na Fotografia 7. 
Fotografia 7 - I Feira de Empreendedores Mirins realizado na UFLA

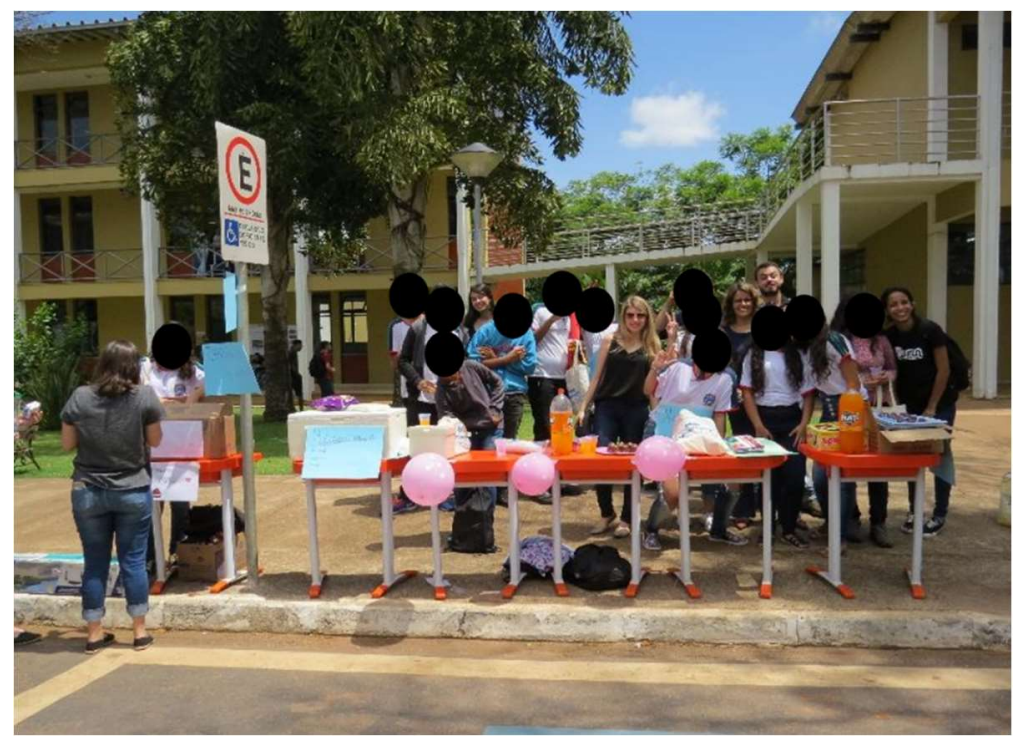

Fonte: Arquivos da pesquisa (2019), dados do projeto.

A realização desse evento foi relevante, pois consistiu no momento em que os alunos puderam colocar em prática o que foi ensinado ao longo do curso. Nesta ocasião, eles tiveram a oportunidade de exercer a criatividade e trabalharem em algo inovador. Os alunos venderam, em sua maioria, artigos do gênero alimentício, como coxinha, geladinho, trufas, bolo gelado, mousse, palha italiana e merengue. Também foram vendidos potes artesanais. Para auxiliar na venda, foram elaborados cartazes contendo a propaganda dos produtos e promoções no caso de compra em maior quantidade.

Os alunos surpreenderam com a dedicação e empenho nas atividades desenvolvidas na Feira. Ao mesmo tempo, eles ficaram extremamente satisfeitos com a quantidade de produtos vendidos e o lucro obtido, o que foi uma forma de motivá-los a serem empreendedores.

\section{Conclusão}

Em 2018, o projeto foi reestruturado visando o desenvolvimento de uma atuação mais aprofundada e longitudinal da temática proposta. Para atender a esse propósito, a segunda versão do projeto passou a concentrar as atividades em apenas uma escola. Assim, este artigo discutiu sobre o processo metodológico utilizado para o desenvolvimento do projeto com os alunos do $9^{\circ}$ ano da escola escolhida, assim como os resultados obtidos. 
A segunda versão do projeto contou com diversas etapas, quais sejam: avaliação e fechamento da primeira etapa do projeto (2015-2017); definição da nova estrutura; definição de responsabilidades temáticas; capacitação; construção das aulas; apresentação e reorganização das aulas; feedbacks da postura a ser utilizada nas aulas; execução do Projeto; reuniões para avaliar as aulas dadas e apresentar as aulas vindouras; organização da I Feira de Empreendedores Mirins; avaliação da segunda etapa do projeto; proposta para a execução do projeto em 2019. Assim, o primeiro semestre de 2018 foi determinado para a capacitação dos membros, elaboração dos materiais e planejamento, ao passo que no segundo semestre de 2018 os membros foram a campo e partiram para a execução.

Não obstante, o projeto contou com diferentes resultados. Primeiramente, os materiais elaborados pelos membros, como os manuais do aluno e professor, slides como instrumento auxiliar para a ministração das aulas, cartilha com história em quadrinhos sobre empreendedorismo e a culminância, que consistiu na realização da I Feira de Empreendedores Mirins.

A partir dos resultados, é possível observar o elevado grau de preocupação dos membros do projeto em fornecer um curso de qualidade à rede municipal de ensino. Assim, o comprometimento da equipe, através da realização de reuniões periódicas, assiduidade na visita à escola e constante busca pelo aperfeiçoamento das aulas, mostrou-se fundamental para o bom resultado.

Ante o exposto, na busca pela criação de um elo entre universidade e sociedade por meio da extensão, o projeto tem provocado mudanças para seus envolvidos. Os alunos são beneficiados com um curso de capacitação, ainda no ensino fundamental, trazendo a possibilidade de seguirem o caminho do empreendedorismo em sua vida profissional. Os membros do projeto adquiriram diversas habilidades ao desenvolverem a didática, elaborarem material teórico e obterem novos conhecimentos. A Universidade encontrou um modo efetivo de propagação de conhecimento.

Assim, vislumbra-se que o projeto traz consigo os elementos caracterizadores do empreendedorismo social: ser inovador; realizável; autossustentável; envolver várias pessoas e segmentos da sociedade, principalmente a população atendida; provocar impacto social e permitir que seus resultados possam ser avaliados.

A contribuição deste artigo é metodológica e social. No que se refere à primeira, trata-se da possibilidade de replicar a proposta metodológica em outros contextos. Já a segunda relacionase ao estímulo do empreendedorismo como alternativa à empregabilidade, podendo ser um caminho para ser traçado pelo jovem em alternativa ou concomitante à Universidade, considerando as suas diferentes facetas, seja o social, o público, o sustentável ou mesmo o privado.

A partir deste projeto, abre-se um campo para novos estudos e projetos de extensão, quais sejam: ampliar o seu raio de atuação, por meio da criação de políticas públicas que incentivem o empreendedorismo na grade curricular do ensino fundamental; a criação de um curso virtual que possa viabilizar a participação de um maior número de jovens sendo contemplados por estes ensinamentos. 


\section{Referências}

ABDO, D.; PARIS, C. M. Social entrepreneurship in the UAE: challenges and recommendations. International Journal of Sustainable Society, v. 9, n. 1, p. 41-60, 2017.

BAGGIO, A. F.; BAGGIO, D. K. Empreendedorismo: Conceitos e definições. Revista de empreendedorismo, inovação e tecnologia, v. 1, n. 1, p. 25-38, 2014.

BORGES, A. F.; LIMA, J. B.; BRITO, M. J. Fundamentos da Pesquisa em Empreendedorismo: aspectos conceituais, teóricos, ontológicos e epistemológicos. In: ENCONTRO NACIONAL DA ASSOCIAÇÃO DE PÓS-GRADUAÇÃO E PESQUISA EM ADMINISTRAÇÃO, 41., 2017, São Paulo. Anais... Rio de Janeiro: ANPAD, 2017.2017.

BRASIL. Constituição da República Federativa do Brasil de 1988. Brasília, DF: Senado Federal, 1988.

COSTA, A. M.; BARROS, D. F.; MARTINS, P. E. M. Linguagem, relações de poder e o mundo do trabalho: a construção discursiva do conceito de empreendedorismo. Revista de Administração Pública, v. 42, n. 5, p. 995-1018, 2008.

DOLABELA, F.; FILION, L. J. Fazendo revolução no Brasil: a introdução da pedagogia empreendedora nos estágios iniciais da educação. REGEPE-Revista de Empreendedorismo e Gestão de Pequenas Empresas, v. 2, n. 3, p. 134-181, 2013.

DRUCKER, P. F. Inovação e espírito empreendedor. São Paulo: Pioneira, 1987.

MAIR, J.; MARTI, I. Social entrepreneurship research: A source of explanation, prediction, and delight. Journal of world business, v. 41, n. 1, p. 36-44, 2006.

MURAD, E. P.; CAPPELLE, M. C. A.; ANDRADE, D. M. Mensuração e avaliação de impacto social de empreendimentos sociais. Revista Pensamento Contemporâneo em Administração, v. 14, n. 3, p. 63-78, 2020.

OLIVEIRA, E. M. Empreendedorismo social no Brasil: atual configuração, perspectivas e desafios-notas introdutórias. Revista da FAE, v. 7, n. 2, 2004.

OSTERWALDER, A.; PIGNEUR, Y. Business model generation: a handbook for visionaries, game changers, and challengers. Nova Jersey, EUA: John Wiley \& Sons, 2010.

PAULA, J. A. A extensão universitária: história, conceito e propostas. Interfaces-Revista de Extensão da UFMG, v. 1, n. 1, p. 5-23, 2013. 
PEREDO, A. M.; MCLEAN, M. Social entrepreneurship: A critical review of the concept. Journal of world business, v. 41, n. 1, p. 56-65, 2006.

RODRIGUES, A. L. L. et al. Contribuições da extensão universitária na sociedade. Caderno de Graduação-Ciências Humanas e Sociais-UNIT, v. 1, n. 2, p. 141-148, 2013.

SCHMIDT, S.; BOHNENBERGER, M. C. Perfil empreendedor e desempenho organizacional. Revista de Administração Contemporânea, v. 13, p. 450-467, 2009.

SECCHI, L. Modelos organizacionais e reformas da administração pública. Revista de Administração Pública, v. 43, p. 347-369, 2009.

SIMÕES, G. L.; SIMÕES, J. M. Reflexões sobre o conceito de participação social no contexto brasileiro. Jornada Internacional de Políticas Públicas, v. 7, 2015.

SOUZA, S. A. A introdução do empreendedorismo na educação brasileira: primeiras considerações. Educação \& Linguagem, v. 15, n. 26, p. 77-94, 2012.

VALE, G. M. V.; CORRÊA, V. S.; REIS, R. F. Motivações para o empreendedorismo: necessidade versus oportunidade? Revista de Administração Contemporânea, v. 18, p. 311-327, 2014. 